\title{
Physical, chemical and antimicrobial implications of the association of propolis with a natural rubber latex membrane
}

\author{
Daniela Cervelle Zancanela ${ }^{\mathrm{a}, *}$, Rondinelli Donizetti Herculano ${ }^{\mathrm{b}}$, Cristiano Soleo Funari ${ }^{\mathrm{c}}$, \\ Caroline Maria Marcos ${ }^{\mathrm{b}}$, Ana Marisa Fusco Almeida ${ }^{\mathrm{b}}$, Antônio Carlos Guastaldi ${ }^{\mathrm{a}}$ \\ a São Paulo State University (UNESP), Institute of Chemistry, Araraquara, São Paulo, Brazil \\ b São Paulo State University (UNESP), School of Pharmaceutical Sciences, Araraquara, São Paulo, Brazil \\ 'São Paulo State University (UNESP), Faculty of Agricultural Sciences, Botucatu, São Paulo, Brazil
}

\section{A R T I C L E I N F O}

Article history:

Received 18 April 2017

Received in revised form 7 July 2017

Accepted 22 July 2017

Available online 23 July 2017

\section{Keywords:}

Skin wound healing

Antifungal

Cicatrizant

Propolis release

\begin{abstract}
A B S T R A C T
Natural rubber latex (NRL) has shown interesting biomedical properties, such as wound healing improvement, tissue regeneration stimulation and angiogenesis. Propolis, produced by honey bees, acts as an antiseptic agent in beehives. It has been used in ethnopharmacology as an antimicrobial and cicatrizant agent over centuries. The aim of this study was to incorporate propolis into an NRL membrane whilst keeping the antibiotic properties of the former against microorganisms often associated with wound healing delay and the chemical and physical characteristics of the latter. This work has shown that the interactions between the NRL and the propolis constituents were not due to chemical bonding. The propolis-NRL membrane constituents in simulated body fluid were released gradually, reaching $37 \%$ release in $144 \mathrm{~h}$. The concentration of released material of $400 \mu \mathrm{g} / \mathrm{mL}$ was able to inhibit $80 \%$ of the growth of $C$. albicans. The incorporation of propolis extract into a NRL membrane while keeping the desirable characteristics of both has been demonstrated to be feasible. Therefore, this association might be used as an auxiliary in wound healing processes.
\end{abstract}

(c) 2017 Elsevier B.V. All rights reserved.

\section{Introduction}

Natural Rubber Latex (NRL) membranes from Hevea brasiliensis are important inductors of the wound healing process and are used in several medical applications, such as in prosthetics and bone grafting $[1,2]$. In addition, the treatment of diabetic and phlebopathic ulcers with NRL membranes leads to faster healing due to a vascular growth factor found in NRL, together with the physical blockage to exposure to new infectious agents at the damaged site. Some of the interesting features of NRL membranes are biocompatibility, capacity to stimulate angiogenesis, easy manipulation, low cost and high mechanical resistance [2].

Propolis is a complex mixture of varying resinous, gummy and balsamic materials produced by Apis mellifera $L$. from plant parts, pollen, bee salivary secretions and wax with the purpose of sealing and protecting beehives against infecting microorganisms, among others [3]. In addition to its wide use in ethnopharmacology, its persistent use as a cicatrizant agent over the centuries is one of its most popular uses [4]. A wide range of biological activities of

\footnotetext{
* Corresponding author.

E-mail address: daniela.zancanela@iq.unesp.br (D.C. Zancanela).
}

propolis that may be related to skin healing have been reported in the specialized literature, such as antibacterial, antifungal, skin cell proliferation enhancer, among others [5,6].

The aim of this work was to incorporate propolis into a NRL membrane while keeping its antibiotic properties against microorganisms often associated with wound healing delay and the physical and chemical characteristics of the latter. For that, the following parameters were investigated: (i) the physical and chemical interactions between the NRL membrane and propolis, (ii) the release of propolis constituents from the NRL membrane in simulated body fluid (SBF), (iii) the ability of the released compounds to act as antimicrobial agents and (iv) the effect of the incorporation of propolis into NRL on the membrane mechanical resistance.

\section{Materials and methods}

A propolis extract was produced using a crude dry propolis (ApisFlora, Brazil) sample in EtOH- $\mathrm{H}_{2} \mathrm{O}(7: 3 \mathrm{v} / \mathrm{v})$ solution [7]. NRL (BDF Rubber Latex Co. Ltd., Brazil) was extracted, centrifuged and kept in an ammonia solution [1,8]. A propolis-NRL membrane was obtained by adding $1 \mathrm{~mL}$ of propolis extract to $3 \mathrm{~mL}$ of NRL 
in Petri dishes and kept at room temperature for $24 \mathrm{~h}$. Pure NRL membranes were also prepared as a control.

Membrane tensile were carried out in a Universal testing machine - EMIC Model DL 2000 with a $50 \mathrm{kgf}$ load cell at $500 \mathrm{~mm} / \mathrm{min}$ and elongated until failure, following ASTM standard D412. The propolis extract, the pure NRL membrane and the propolis-NRL membrane were characterized by FTIR directly by the attenuated total reflection (ATR) method using a TENSOR 27 (Bruker, Germany) (4000-500 $\mathrm{cm}^{-1}$ ) with a resolution of $4 \mathrm{~cm}^{-1}$ and 32 scans [1]. For the compound release study of the propolis-NRL membrane, the membrane was placed into a $10 \mathrm{~mL}$ SBF solution. The release behavior was investigated by analyzing aliquots of the solution at predetermined time intervals for $216 \mathrm{~h}$ by UV-VIS spectroscopy $(216 \mathrm{~nm})$. The amount of substance released was calculated by means of the Lambert Beer law and the line equation was obtained by linear regression of the analytical calibration curve of the extract [8].

The propolis extract produced was evaluated against C. albicans (ATCC 90028, from the Laboratory of Clinical Mycology, Depart-

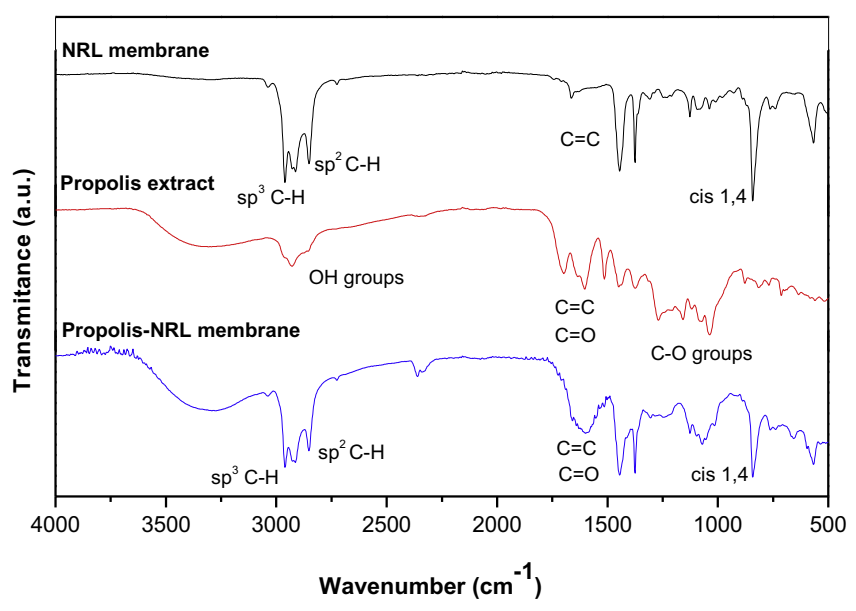

Fig. 1. FTIR-ATR spectra of propolis extract and NRL membranes. ment of Clinical Analysis, Faculty of Pharmaceutical Sciences of UNESP in Araraquara). The minimum inhibitory concentration (MIC) was determined using the microdilution method described in document M27-A2 from the Clinical Laboratory Standards Institute (CSLI) with serial dilutions of the propolis extract in a RPMI culture medium. The NRL membranes with and without propolis extract were also evaluated for their activities against $C$. albicans. The material released in SBF at $400 \mu \mathrm{g} / \mathrm{mL}$ was tested in RPMI culture medium for $24 \mathrm{~h}$.

\section{Results}

FTIR-ATR (Fourier Transform Infrared-Attenuated Total Reflection) was used to characterize the interactions among NRL and the propolis constituents. Fig. 1 shows the spectra of the propolis extract and NRL membranes with and without propolis extract.

The spectrum of the pure NRL membrane showed bands characteristic of cis 1,4-polyisoprene at 1375, 1445, 2859 and $2961 \mathrm{~cm}^{-1}$ (Fig. 1) as expected [8]. The propolis extract presented characteristic bands at $1640,1457,1252 \mathrm{~cm}^{-1}$ typical of aromatic rings and polyols and flavonoids, among other classes of compounds [10] (Fig. 1). The propolis-NRL membrane spectrum showed a sum of the bands observed in the separate analyses of the NRL membrane and propolis (Fig. 1). Moreover, no molecular interactions were observed between propolis and the NRL membrane, suggesting that the interactions between the membrane and the propolis compounds were physical (physical adsorption). This is a desirable behavior, since it allows the release of propolis compounds from the membrane into the wound environment.

Fig. 2 shows the gradual release of propolis constituents by the propolis-NRL membrane over $216 \mathrm{~h}$ in a SBF solution.

The large amount of propolis extract compounds released from the propolis-NRL membrane that occurred before stability was reached is called "burst release" $(0-5 \mathrm{~h})$ (Fig. 2). In the first hour, the membrane released almost $15.8 \%$ of propolis extract compounds and in the first $24 \mathrm{~h}$, about $22 \%$. The release continued up to $37.35 \%$ in $144 \mathrm{~h}$, when the concentration became constant (Fig. 2). The release depends mainly on the amount of compounds present in the polymer bulk (encapsulated material) versus the

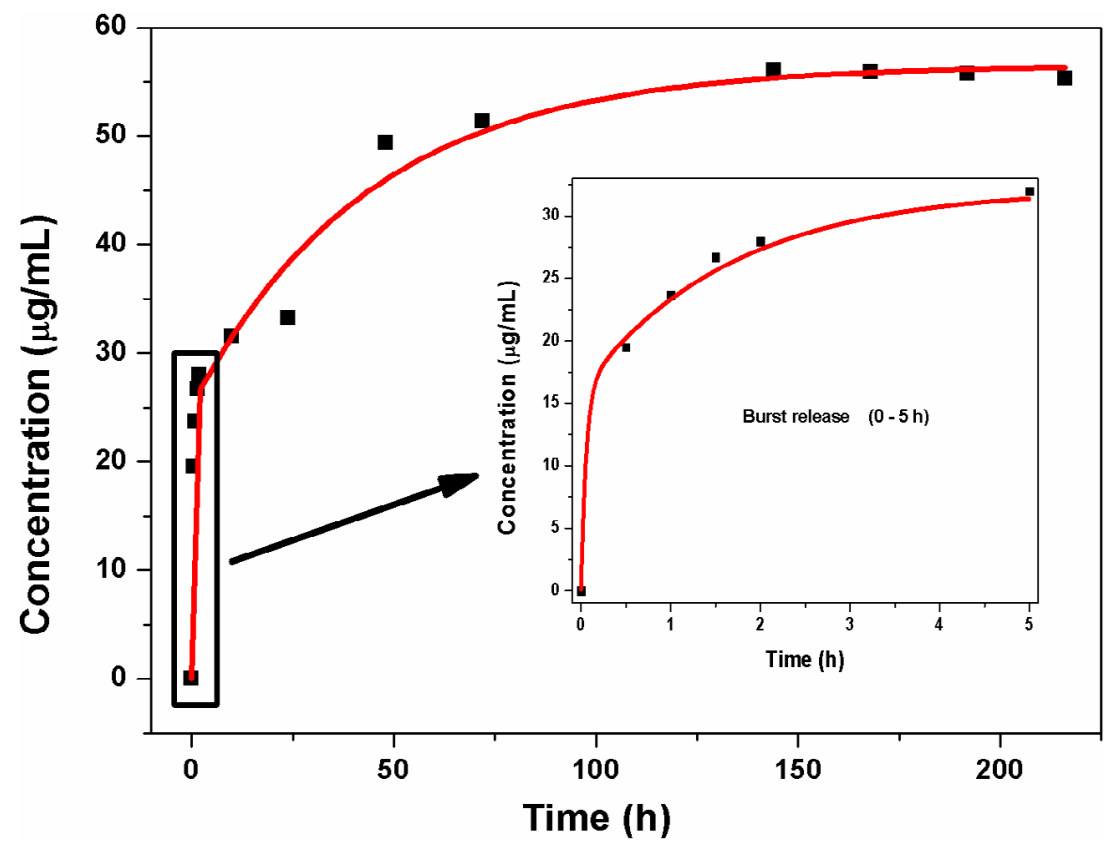

Fig. 2. Propolis extract release kinetics from NRL membranes in SBF. Insert: First 5-h release. 


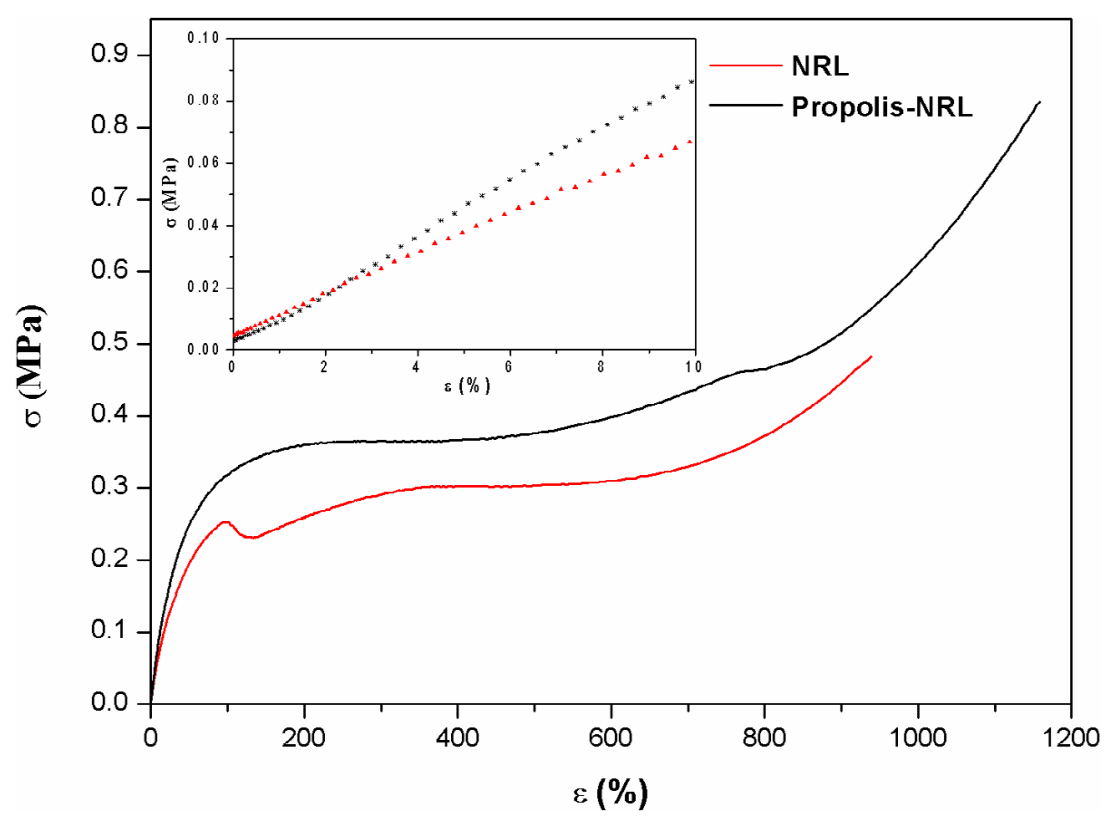

Fig. 3. Mechanical resistance of membranes with and without propolis extract. The inset shows the initial part of the stress-strain curves.

amount of compounds adsorbed onto the membrane surface. Adsorbed compounds are released faster than polymerencapsulated compounds (reservoir) due to differences in the intensity of the interaction, which are weaker on the surface [1]. The release obeys a bi-exponential function, $Y_{(t)}=Y_{0}+A_{1} e^{-t / \tau 1}$ $+A^{2} e^{-t / \tau 2}$, where $Y_{(t)}$ is the amount of propolis extract in the NRL membrane at a given time, $t, Y_{0}$ is the initial content of extract, $\mathrm{A}_{1}$ and $\mathrm{A}_{2}$ are constants and $\tau_{1}$ and $\tau_{2}$ are characteristic times. The values of constants $A_{1}$ and $A_{2}$ and characteristic times $\tau_{1}$ and $\tau_{2}$ of the NRL membrane were $25.1664,-31.3815,0.3545$ and 44.1052 , respectively. Franca et al. [11] found that about $20 \%$ of propolis compounds in chitosan varnish membranes containing 5 and $15 \%(\mathrm{w} / \mathrm{v})$ of propolis extract were released during the first $24 \mathrm{~h} \mathrm{[11].} \mathrm{On} \mathrm{the} \mathrm{other} \mathrm{hand,} \mathrm{Borges} \mathrm{et} \mathrm{al.} \mathrm{[8]} \mathrm{observed} \mathrm{that} 80 \%$ of Casearia sylvestris compounds were released from NRL membranes, in contrast to $45 \%$ of oxytocin peptide released by the same polymer [12].

Fig. 3 shows the mechanical strength of the NRL membrane in comparison to the propolis-NRL membrane. Table 1 was put together from the data in Fig. 3. The propolis-NRL membrane presented an increase in tensile strength when compared to the pure NRL membrane (Table 1). This test showed that the presence of propolis does not impair the mechanical resistance of the NRL membrane.

Finally, the potential activity of the propolis compounds released into the SBF towards C. albicans was checked. At $400 \mu \mathrm{g} /$ $\mathrm{mL}, 81.8 \%$ death of $C$. albicans was recorded, versus $13.6 \%$ for the pure NRL membrane, which gave evidence that the propolis compounds released by the membrane maintained their inhibitory activity against $C$. albicans (a $625-\mu \mathrm{g} / \mathrm{mL}$ MIC was observed for pure propolis). Silva et al. [13] showed that the inhibitory effects on the microbiological growth of $C$. albicans were similar for both

Table 1

Mechanical properties of the membranes.

\begin{tabular}{|c|c|c|c|}
\hline Membranes & $\begin{array}{l}\text { Tensile strength } \\
(\mathrm{MPa})\end{array}$ & $\begin{array}{l}\text { Stretch at break } \\
(\%)\end{array}$ & $\begin{array}{l}\text { Young's Module } \\
\text { (MPa) }\end{array}$ \\
\hline Pure NRL & 0.48 & 939.2 & 0.68 \\
\hline $\begin{array}{c}\text { Propolis- } \\
\text { NRL }\end{array}$ & 0.84 & 1158.2 & 1.04 \\
\hline
\end{tabular}

membranes, possibly because they covered the culture surfaces and their surfaces provided poor cell adhesion.

\section{Conclusion}

This work demonstrated that the investigated propolis-NRL membrane kept the desirable characteristics of both materials to potentially act as an auxiliary in wound healing.

\section{Acknowledgements}

The propolis sample was kindly provided by ApisFlora Ltda. The authors thank CAPES, CNPq and FAPESP (Process 2014/17526-8) for the financial support.

\section{References}

[1] F.A. Borges, E. de Almeida Filho, M.C.R. Miranda, M.L. dos Santos, R.D. Herculano, A.C. Guastaldi, Natural rubber latex coated with calcium phosphate for biomedical application, J. Biomater. Sci. Polym. Ed. 26 (2015) 1256-1268.

[2] M. Ferreira, R.J. Mendonça, J. Coutinho-Neto, M. Mulato, Angiogenic properties of natural rubber latex biomembranes and the serum fraction of Hevea brasiliensis, Braz. J. Phys. 39 (2009) 564-569.

[3] C.S. Funari, V.O. Ferro, M.B. Mathor, Analysis of propolis from Baccharis dracunculifolia DC. (Compositae) and its effects on mouse fibroblasts, J. Ethnopharmacol. 111 (2007) 206-212.

[4] S. Castaldo, F. Capasso, Propolis, an old remedy used in modern medicine, Fitoterapia 73 (Suppl. 1) (2002) S1-S6.

[5] E. Sehn, L. Hernandes, S.L. Franco, C.C.M. Gonc, M.L. Baesso, Analytica chimica acta dynamics of reepithelialisation and penetration rate of a bee propolis formulation during cutaneous wounds healing, Anal. Chim. Acta 635 (2009) $115-120$.

[6] S. Boisard, A.M. LeRay, A. Landreau, M. Kempf, V. Cassisa, C. Flurin, P. Richomme, Antifungal and antibacterial metabolites from a French poplar type propolis, Evid. Based Complement. Alternat. Med. (2015). doi:10.1155/2015/ 319240.

[7] C.S. Funari, R.L. Carneiro, M.E. Creese, G.M. Leme, A.J. Cavalheiro, E.F. Hilder, On track for a truly green propolis - fingerprinting propolis samples from seven countries by means of a fully green approach, ACS Sustainable Chem. Eng. 4 (2016) 7110-7117.

[8] F.A. Borges, L.F.C. Bolognesi, A. Trecco, B.C. Drago, L.B. Arruda, P.N. Lisboa Filho, E.G. Pierri, C.F.O. Graeff, A.G. Santos, M.C.R. Miranda, R.D. Herculano, Natural rubber latex: study of a novel carrier for Casearia sylvestris Swartz Delivery, ISRN Polym. Sci. (2014). doi:10.1155/2014/241297.

[10] R.N. Oliveira, M.C. Mancini, F.C.S. Oliveira, T.M. Passos, B. Quility, R.M.S. Thiré, G.B. Mcguiness, FTIR analysis and quantification of phenols and flavonoids of 
five commercially available plants extracts used in wound healing, Matéria (Rio J.) 21 (2016) 767-779.

[11] J.R. Franca, M.P. de Luca, T.G. Ribeiro, R.O. Castilho, A.N. Moreira, V.R. Santos, A. A.G. Faraco, Propolis - based chitosan varnish: drug delivery, controlled release and antimicrobial activity against oral pathogen bacteria, BMC Complement. Altern. Med. 14 (2014) 478.
[12] N.R. Barros, M.C.R. Miranda, F.A. Borges, R.J. Mendonça, E.M. Cilli, R.D. Herculano, Oxytocin sustained release using natural rubber latex membranes, Int. J. Pept. Res. Ther. 22 (2016) 435-444.

[13] A.J. Silva, J.R. Silva, N.C. de Souza, P.C.S. Souto, Membranes from latex with propolis for biomedical applications, Mater. Lett. 116 (2014) 235-238. 